\title{
Editorial
}

Francesco Asdrubali*

\section{Noise Mapping: a first balance and future perspectives}

https://doi.org/10.1515/noise-2020-0007

Received Apr 06, 2020; accepted Apr 17, 2020

It was almost six years ago - in June 2014 - when I wrote the Editorial "New frontiers in Environmental Noise", officially the first paper appeared in Noise Mapping.

Since then, the Journal has experienced a constant growth and has gained a reputation in the international context as the main publishing option for authors writing on noise mapping and related topics.

The Journal has become a hub integrating the relevant research communities in the fields of environmental noise and soundscape studies. Many high quality research papers have been published in all the different fields of environmental acoustics, and in particular:

- noise mapping and noise action plans: case studies;

- models and algorithms for source characterization and outdoor sound propagation: proposals, applications, comparisons, round robin tests;

- local, national and international policies and good practices for noise mapping, planning, management and control;

- evaluation of noise mitigation actions;

- evaluation of environmental noise exposure;

- actions and communications to increase public awareness of environmental noise issues;

- outdoor soundscape studies and mapping;

- classification, evaluation and preservation of quiet areas;

- characterization of the emissions of the following sources: roads, railways, airports and aircrafts, harbors and ships, industrial plants, leisure and night-life activities, urban areas, natural sound sources.

Also the Editorial Advisory Board of the Journal has experienced a growth: the initial Board has been enlarged during the years, up to include 20 members from all the continents (except Africa) and the different geographic areas and from the various research fields of environmental acoustics.

I would like to thank all of them for their valuable contributions, and especially those who served as reviewers and Guest Editors for the Special Issues. A particular thanks to Francesco D’Alessandro, whose reliable work as Assistant Editor is precious.

As a matter of fact, three successful Special Issues characterize the first years of the Journal:

- a Special Issue on Environmental Noise Aspects in EU funded projects, started in 2015, with Gaetano Licitra as Guest Editor. The EU environmental policy, since the issue of the Noise Directive 2002/49/EC, has always given a great importance to noise pollution and its prevention and mitigation. As stated by the European Environmental Agency in the report "Noise in Europe 2014", noise pollution is a growing concern in Europe with severe health, social and economic drawbacks. For this reason, several research and dissemination projects have been funded in this field, within various EU programmes (LIFE, 7FP, H2020, Interreg, ENPI MED). The Special Issue presented a great variety of different projects, characterized by large European partnerships, dealing with reducing emissions from various sources, optimizing

^Corresponding Author: Francesco Asdrubali: Editor in Chief

ə Open Access. ( 2020 F. Asdrubali, published by De Gruyter. (cc) BY This work is licensed under the Creative Commons 
management and planning of noise issues, defining and protecting quiet areas, using sustainable or innovative solutions to tackle noise pollution, evaluating the effect of noise on human health, increase citizens' awareness. The Special Issue has the merit of having being an Open Access, powerful dissemination tool for the outcomes of these studies; 18 papers were altogether published;

- a Special issue on Recent Advances on Soundscape Research, started in 2016, with Luis Bento Coelho as Guest Editor. A fair amount of research on soundscape has been conducted in recent years by various teams all over the world focusing on understanding, managing, and designing soundscapes. The 2009-2013 European COST initiative "Soundscape of European Cities and Landscape", as well as the standard ISO 12913 parts 1 and 2, boosted research in this field. The Special Issue aimed to disseminate new research results dealing with different soundscape themes, such as Language and meaning, Understanding soundscape, Soundscape planning and design, Soundscape mapping and Case studies; 11 papers were altogether published;

- a Special Issue on Smart acoustic solutions for smart cities, started in 2018, with Sergio Luzzi as Guest Editor. Future smart cities will be made of connected infrastructures able to talk each other and to adapt to citizens' needs. Smart sensors and monitoring systems will help cities to improve their services on a real time basis. In the near future every one of us will be able to collect and share noise data with its own smartphone or with sensors much cheaper than professional expensive sound level meters. The Special Issue presented several innovative studies, especially in Europe, in the field of smart acoustic monitoring; 5 papers were altogether published.

The success of the Journal is also demonstrated by the indexation in Web of Science (obtained in 2017) and in Scopus (obtained in 2018) and by the very good citation scores obtained in 2019:

- CiteScore 2018: 3.18;

- SCImago Journal Rank (SJR) 2018: 0.501;

- Source Normalized Impact per Paper (SNIP) 2018: 1.328.

The following statistics related to the journal confirm its growth in the last years and its international dimension:

- since the beginning, the number of the authors of published papers is equal to 327 from 56 different countries;

- the number of reviewers is equal to 265 from 48 different countries,

- the number of papers downloads has grown from 3514 in 2017 till 4517 in 2019.

The significant results obtained by the Journal are however a starting point and not an arrival. The future perspectives of the Journal include three new Special Issues.

The first, entitled "Understanding the Impact of Electric and Autonomous Vehicles on Urban Noise Pollution", is related to an emerging topic in urban mobility. Innovative studies that establish novel links between noise mapping in urban areas and traffic simulation in the context of electric and automated mobility are welcome. Research in the field of Electric vehicles (EVs) - which include a variety of technologies such as plug-in hybrid electric vehicles (PHEVs), battery electric vehicles (BEVs) and hybrid electric vehicles (HEVs), as well as Autonomous Vehicles (AVs), are the topic of this Special Issue. The call for paper is inter-disciplinary, and accepts works from fields of engineering, economics, planning, policy, business and management, as well as any other disciplines that contribute to the scientific understanding of the impact of electric and automated mobility on noise emission in urban areas.

The second one will be dedicated to "The noise climate at the time of COVID-19 virus". All the world, even though at different extent, is facing the spread of COVID-19 virus and the relevant diseases. In the attempts to delay, and hopefully, reduce the virus transmission among individuals, National Governments are implementing severe restrictions, limiting individual mobility, transportation, production of non-essential goods and so forth. These restrictions are producing a rapid and awesome change of the lyfe-style in urban areas, also affecting the daily noise climate. This special issue is aimed to collect experiences in various countries regarding the acoustic impact due to the large changes occurring throughout these days. 
Finally, since the Journal is attracting the interest of many researchers from emerging countries, the third Special Issue will be launched in the second half of the year and it will be dedicated to "Noise Mapping in emerging countries”. These countries may have different problems and a legislation under development so it can be interesting to make a focus on the related studies.

Since the beginning, Noise Mapping is open-access and offers a fast and comprehensive peer-review. To further support its reputation and impact, no publication fees will apply until the end of 2020.

I am looking forward to receiving your papers!

Francesco Asdrubali, Editor in Chief 